\title{
CONVENTIONAL MORTGAGE INTEREST RATE AND THE EFFECTIVE FEDERAL FUNDS RATE PASS-THROUGH
}

\author{
Natalie Hegwood \\ Sam Houston State University • Huntsville, Texas \\ M.H. Tuttle \\ Sam Houston State University • Huntsville, Texas
}

\section{ABSTRACT}

This paper examines the response of the conventional thirty-year mortgage interest rate to changes in the effective federal funds rate. The results indicate complete pass-through; in the long run, the conventional mortgage interest rate responds in a one-to-one manner with the effective federal funds rate. Further, results suggest the conventional mortgage interest rate responds symmetrically to changes in the effective federal funds rate in the long run. In the short run, large, frequent increases in the effective federal funds rate create larger increases in the mortgage interest rate relative to periods where the federal funds rate is rising slowly or falling. Our results suggest a long-run mortgage interest rate adjustment halflife of approximately twenty months in response to an effective federal funds rate change.

JEL Codes: C22, E43

Key Words: Thirty-year Conventional Mortgage Interest Rate, Effective Federal Funds Rate, Asymmetric Adjustment, Pass-Through

\section{INTRODUCTION}

Given the recent volatility in housing markets, understanding the impact that Federal Reserve policy has on the mortgage interest rate is vital. Changes in monetary policy through effective federal funds rate changes affect market rates of interest. Previous research notes the importance of understanding the magnitude and timing of this effect. Sellon (2002) notes that the degree of interest rate passthrough and speed of adjustment are critical to understanding the effectiveness of the monetary transmission mechanism and of monetary policy. This study contributes to the literature by examining both the long-run and short-run dynamic relationships between the conventional thirty-year mortgage interest rate and the effective federal funds rate using three threshold auto-regressive models that are common in the current literature. 


\section{LITERATURE REVIEW}

Two critical issues arise when considering the impact of changes in the effective federal funds rate on other credit market rates. First, one must consider the degree to which a given change in the effective federal funds rate passes through to, or changes, the conventional thirty-year mortgage interest rate in the long run. More specifically, long-run pass-through measures the magnitude of the change in the mortgage interest rate in the long run from a change in the effective federal funds rate. In the long run, the mortgage interest rate will change, moving the rate towards its long-run equilibrium value. The long-run adjustment of the mortgage interest rate to equilibrium takes place over several months. Therefore, one must consider the short-run, transitory effect of changes in the effective federal funds rate on the mortgage interest rate. These short-run changes include the immediate impact of changes in the federal funds rate on the mortgage interest rate and the mortgage interest rate's speed of adjustment, or how quickly the mortgage interest rate moves to its long-run equilibrium value.

The degree of pass-through between the effective federal funds rate to the conventional thirty-year fixed mortgage interest rate has become a popular way to assess the effectiveness of monetary policy. Pass-through is traditionally examined by testing for cointegration between the two interest rates. Finding that these two series are cointegrated suggests that they share a long-run equilibrium relationship. Traditionally, research supports cointegration between these two interest rates, meaning that these two interest rates move together in the long run. Further, the cointegration results provide the degree of long-run pass-through.

Granger and Newbold (1974) note, however, that Ordinary Least Squares regression (OLS) may lead to spurious results when using time-series data. In the interest rate pass-through literature, the Engle-Granger (1987) test is commonly used to overcome the problem of spurious regression. In the Engle-Granger (EG) test, one performs OLS on the variables. The residuals are then subjected to a unit root test in which the null hypothesis is no cointegration and the alternative is cointegration. If one rejects the null hypothesis, then the coefficient on the regressor is an estimate of the degree of pass-through. The cointegration literature notes, however, that the EG method may lead to biased parameter estimates, and in the context of interest rates, biased measures of pass-through. Banerjee et al. (1993) show that the EG method omits short-run dynamics, and it is the omission of these dynamics that potentially leads to biased results.

The current literature reaches mixed results concerning the degree of pass- 
through in the long run. Payne (2006a, 2006b, and 2007) uses the EG method to test for cointegration and measure pass-through. Payne (2006a) notes that switching costs and informational market asymmetries may lead to incomplete pass-through from the effective federal funds rate to the conventional thirty-year mortgage interest rate. Payne (2006a) finds cointegration and incomplete pass-through for the period April 1971 through October 2005. In a later paper, Payne (2006b) finds cointegration with incomplete pass-through using a shorter sample (February 1987 through January 1994), which corresponds to the duration of the specific monetary policy of federal funds rate targeting. In similar work, Payne (2007) finds cointegration with incomplete pass-through in the adjustable mortgage interest rate.

In contrast, citing the potential bias of the EG method in estimating the cointegrating coefficient, Cook (2008) uses an approach by Bardsen (1989) and finds complete pass-through from the effective federal funds rate to the conventional thirty-year fixed mortgage rate. Hegwood and Tuttle (2013) examine the effect of using the Engle-Granger method when estimating the long-run relationship between short-run interest rates and long-run interest rates on government debt for several countries. Their results suggest that the Engle-Granger method potentially biases the long-run estimates by an average of 38.4 percent.

In this research, we employ an alternate, yet common test for cointegration. Using this common test, we find evidence of complete pass-through in the long run. This result suggests that mortgage lenders, on average, maintain a constant margin above the effect federal funds rate in the long run.

In addition to the degree of pass-through, the short-run pattern of adjustment to the long run equilibrium is also of interest. Multivariate tests of symmetric versus asymmetric long run adjustment take the form of threshold autoregressive (TAR), where the threshold is set to zero and where the threshold is endogenously determined, or momentum-threshold autoregressive (MTAR) models (Enders and Siklos, 2001). Payne (2006a) uses an MTAR model and finds long-run symmetric adjustment for the conventional thirty-year fixed mortgage rate. However, for the shorter period, Payne (2006b) finds long-run asymmetric adjustment. In similar work, Payne (2007) finds long-run asymmetric adjustment when examining the relationship between the effective federal funds rate and the adjustable mortgage rate. This research (Payne 2006a, 2006b, and 2007), however, tests for long-run asymmetric adjustment only. The exclusion of short-run asymmetries may bias the long-run asymmetry results.

In this research, we test for long-run and short-run asymmetric adjustment in both interest rates using all three threshold models. Our findings show that the 
mortgage interest rate responds symmetrically to federal funds rate changes in the long run to changes, which supports Payne's findings (2006a and 2007). In the short run, however, the mortgage interest responds asymmetrically to federal funds rate changes when there are "large," frequent increases in the federal funds rate over a relatively short period.

\section{DATA AND UNIT ROOT TESTS}

The monthly thirty-year conventional mortgage interest rate (MR) and the effective federal funds rate (EFF) are available from the Federal Reserve Bank of St. Louis FRED database. The range is April 1971 through February 2016. Due to the time-series nature of the data, we test for nonstationarity using traditional unit root tests. As noted by Granger and Newbold (1974), if the two series are non-stationary and have a single unit root, then OLS will lead to spurious results. Table 1 reports the results from the Augmented Dickey-Fuller (ADF) test (Dickey and Fuller 1979) and the Kwiatkowski, Phillips, Schmidt, and Shin (KPSS) test (Kwiatkowsi et. al 1992). ${ }^{1}$

The preponderance of evidence from these unit root tests suggests that both series are non-stationary, i.e. I(1), which supports findings in previous research. The presence of a structural break, however, may lead to the rejection of the null hypothesis of nonstationarity. Perron (1989) has shown that a series that is stationary around an occasionally shifting mean or trend will mimic the behavior of a random walk and lead to failure to reject a unit root. We therefore test the two interest rates for a unit root using Perron-Voglesang (1992) unit root tests that include a single shift of the mean. We employ both an additive outlier (AO) test with an instantaneous single mean shift and an innovational outlier (IO) test in which the shift occurs over time.

The AO test is a two-stage process, first running the following regression on each time series:

$$
y_{t}=\mu+\delta D U_{t}+u_{t}
$$

The intercept break dummy variable, $D U_{t}$, equals 1 for all $t$ greater than the break date, $T B$, and zero otherwise. The residuals, $u_{t}$ are saved and regressed against their lagged value and lagged differences in the second stage of the procedure as follows:

\footnotetext{
${ }^{1}$ The null hypothesis under the ADF test is non-stationarity of the series, while the null hypothesis under the KPSS test is stationarity of the series.
} 


$$
\Delta u_{t}=\sum_{i=0}^{k} \omega_{i} D(T B)_{t-i}+\rho u_{t-1}+\sum_{j=1}^{k} c_{j} \Delta u_{t-j}+\varepsilon_{t}
$$

The number of lagged differences, $k$, is determined by the max-to-min method, with $k$ max set at eight. The dummy variables $D(T B)_{t-i}$ equal 1 if $t=\mathrm{TB}+1$ and zero otherwise. The two regressions are estimated sequentially for each possible break year, $T B=k+2, \ldots T-1$ where $T$ is the number of observations. The break date is chosen to minimize the t-statistic on $\rho$. The unit root null hypothesis is rejected if the minimum t-statistic on $\rho$ is less than the appropriate critical value. As shown in table 1, we fail to reject the null hypothesis of a unit root for both the federal funds rate and the thirty-year conventional mortgage rate. Critical values are taken from Perron-Vogelsang (1992).

The IO test involves running the following regression on each series:

$$
y_{t}=\mu+\delta D U_{t}+\theta D(T B)_{t}+\alpha y_{t-1}+\sum_{i=1}^{k} c_{i} \Delta y_{t-i}+\varepsilon_{t}
$$

Where $D U$ and $D(T B)$ are the same as in the AO test. The max-to-min procedure is again used to choose the number of lagged differences, $k$. The break date, $T B$, is chosen to minimize the t-statistic on $\alpha$.

The results, shown in table 1, fail to reject the null hypothesis of a unit root based on critical values from Perron-Vogelsang (1992). We therefore conclude that both the effective federal funds rate and the conventional thirty-year mortgage rate are non-stationary processes, and that this result is robust to the addition of a potential structural change in the mean. Therefore, cointegration tests are appropriate, because the use of OLS leads to spurious results (Granger and Newbold 1974). 
Table 1

Unit Root Tests

\begin{tabular}{|c|c|c|c|c|}
\hline & \multicolumn{4}{|c|}{ Test Statistics } \\
\hline & Dickey-Fuller & KPSS & $\mathrm{AO}$ & 10 \\
\hline & Intercept Only & Intercept Only & Intercept Only & Intercept Only \\
\hline MR & -0.70 & 1.82 & -2.72 & -2.47 \\
\hline EFF & -1.98 & 1.93 & -3.20 & -3.47 \\
\hline$\Delta \mathrm{MR}$ & -17.46 & 0.22 & - & - \\
\hline$\Delta \mathrm{EFF}$ & -5.62 & 0.09 & - & - \\
\hline
\end{tabular}

Critical value for the ADF test statistic at a $5 \%$ level of significance when including a constant only is 2.87. Critical value for the KPSS test statistic is 0.46 when including a constant only. ADF test lags based on Schwarz Criteria. $\Delta$ denotes the first-difference operator. The ciritcal value for both the AO and IO test statistics at a $5 \%$ level of sisnificance is -4.44 .

\section{COINTEGRATION METHODS AND RESULTS}

Cointegration is tested between the two series, given that they both appear to be non-stationary. Banerjee et al. (1993) show that omission of short-run dynamic elements in the Engle-Granger procedure may lead to biased estimates. For example, Cook (2008) and Hegwood and Tuttle (2013) note that the size of the bias in the Engle-Granger method may be large and result in finding incomplete pass-through. Further, the Engle-Granger procedure has also been shown to possess low power in the presence of asymmetric adjustment to the long run equilibrium (Enders and Siklos, 2001).

This research uses the method of Johansen (1991) to test for a long-run relationship between the two series. The Pantula Principle, as suggested by Hjelm and Johansson (2005), is used to identify the proper restrictions on deterministic components. These restrictions include the potential addition of a constant and/or time-trend in the long-run relationship. We start with the least restrictive model until cointegration is achieved. The results suggest the inclusion of an unrestricted constant only. Therefore, the long-run and short-run relationships include a constant and exclude a time trend.

The results of the Johansen cointegration test are provided in Panel A of Table 2. We reject the null of zero cointegrating vectors and fail to reject the null 
of at least one cointegrating vector. Therefore, the result suggests the two series are cointegrated. From the Johansen test, the long-run parameter on the effective federal funds rate, $\theta_{1}$, suggests positive co-movement between the two interest rates, with a long-run parameter of 0.899; a one percentage point increase in the effective federal funds rate will results in a 0.899 percentage point increase in the conventional mortgage interest rate in the long run.

Table 2

Cointegration Test Results

Panel A, Johansen Test Results

\begin{tabular}{ccc} 
& & $95 \%$ Critical \\
Number of Cointegrating Vectors & Trace Statistic & Value \\
Zero & 33.43 & 15.49 \\
$\leq$ One & 1.96 & 3.84 \\
\hline Long-Run Parameter & EFF $\left(\theta_{1}\right)$ & Constant $\left(\theta_{2}\right)$ \\
& 0.899 & 3.446 \\
& $(0.062)$ &
\end{tabular}

Panel B, Test of Long-Run Pass-Through

$\begin{array}{cc} & \text { p-value } \\ \mathrm{H}_{0}: \theta_{1}=1 & 0.222\end{array}$

Standard errors in parenthesis.

As mentioned earlier, ambiguity exists concerning pass-through in previous research. Payne's results (2006a and 2006b) suggest incomplete pass-through. Cook (2008), however, notes that the Engle-Granger method suffers from severe bias. When Cook corrects for this bias, results yield complete pass-through. Panel B of Table 2 provides the results from testing the null hypothesis of complete pass-through $\left(\theta_{1}=\right.$ 1). In Panel B, we fail to reject the null hypothesis of complete pass-through, which supports the finding of Cook. If there is complete pass-through, then our results show that mortgage lenders attempt to maintain, on average, a constant margin of approximately 3.45 percentage points in the long run, given by the estimate of $\theta_{2}$ in Panel A.

\section{TESTS OF ASYMMETRY AND RESULTS}

Results in the previous section show that the conventional mortgage interest 
rate and the effective federal funds rate move together in the long run. Further, we find that the mortgage interest rate moves in a one-to-one manner, given the failure to reject complete pass-through. These results, however, do not describe the mortgage interest rate's speed of adjustment, nor do they provide the short-run, or immediate impact of the changes in the effective federal funds rate or the conventional mortgage interest rate.

We utilize an error-correction model (ECM) to examine the dynamic behavior of these two interest rates. Specifically, we employ threshold models to test for asymmetric long-run adjustment and asymmetric short-run adjustment in these two interest rates. Previous research utilizes threshold models to test for long-run symmetry only (Payne 2006a, 2006b, and 2007). To test for asymmetric responses, we employ two models: a threshold autoregressive (TAR) model and a momentumthreshold autoregressive (MTAR) model. Equations (1a) and (1b) provide the general form of the error-correction models.

$$
\begin{gathered}
\Delta M R_{t}=I_{t} \delta_{1} \varepsilon_{t-1}+(1-I)_{t} \delta_{2} \varepsilon_{t-1}+\sum_{i=1}^{3} I_{t} \beta_{i} \Delta M R_{t-i}+\sum_{i=1}^{3}(1-I)_{t} \alpha_{i} \Delta M R_{t-i} \\
+\sum_{i=1}^{3} I_{t} \gamma_{i} \Delta E F F_{t-i}+\sum_{i=1}^{3}(1-I)_{t} \pi_{i} \Delta E F F_{t-i}+\rho_{0}+u_{t} \\
\Delta E F F_{t}=I_{t} \mu_{1} \varepsilon_{t-1}+(1-I)_{t} \mu_{2} \varepsilon_{t-1}+\sum_{i=1}^{3} I_{t} \omega_{i} \Delta M R_{t-i}+\sum_{i=1}^{3}(1-I)_{t} \sigma_{i} \Delta M R_{t-i} \\
+\sum_{i=1}^{3} I_{t} \varphi_{i} \Delta E F F_{t-i}+\sum_{i=1}^{3}(1-I)_{t} \lambda_{i} \Delta E F F_{t-i}+\rho_{1}+z_{t}
\end{gathered}
$$

where

$$
\begin{array}{ll}
\operatorname{TAR} & I_{t}=\left\{\begin{array}{l}
1 \text { if } \varepsilon_{t-1} \geq \tau \\
0 \text { if } \varepsilon_{t-1}<\tau
\end{array}\right. \\
\text { MTAR } & I_{t}=\left\{\begin{array}{l}
1 \text { if } \Delta \varepsilon_{t-1} \geq \tau \\
0 \text { if } \Delta \varepsilon_{t-1}<\tau
\end{array}\right.
\end{array}
$$

and

$$
\varepsilon_{t-1}=M R_{t-1}-\theta_{1} E F F_{t-1}-\theta_{2}
$$


In equations (1a) and (1b), $I_{t}$ is the Heaviside Indicator, and its value is determined via the error-correction variable, $\varepsilon_{\mathrm{t}-1}{ }^{2}$ The parameters, $\delta_{1}, \delta_{2}, \beta_{1}$, and $\beta_{2}$ give the long-run, equilibrium adjustment of the conventional mortgage interest rate due to disequilibrium between these two interest rates. In a similar manner, the parameters $\mu$ and $\omega$ provide the long-run adjustment of the effective federal funds rate.

Equation (2) provides the derivation of the error-correction variable; it is derived from the long-run relationship estimated via the Johansen cointegration test. When the error-correction variable equals zero, the mortgage interest rate is at its long-run equilibrium value determined by the cointegration vector estimated via the Johansen test and provided in Table 2. For example, from equation (2), a fall in the effective federal funds rate, during periods of expansionary monetary policy, increases the value of the error-correction variable and the size of the disequilibrium between the two interest rates. The Heaviside Indicator is greater than zero in the TAR models when the error-correction term is positive (or greater than $\tau$ ). During periods of contractionary monetary policy, the error-correction term is negative and the Heaviside Indicator is equal to zero.

One must interpret the MTAR results in a slightly different manner. In the MTAR model, the change in the error-correction term determines the value of the Heaviside Indicator. When the mortgage interest rate is below equilibrium due to contractionary monetary policy, the error-correction term is negative and will increase in subsequent periods towards its equilibrium value of zero. Therefore, the error-correction term increases in these periods and the Heaviside Indicator equals one. When the error-correction term and mortgage interest rate decrease during periods of expansionary monetary policy, the Heaviside Indicator equals zero.

The value of the threshold, $\tau$, is set to zero to provide the first set of TAR results in Table 3. In the TAR results in Table 4 and MTAR results in Table 5, the value of $\tau$ is determined endogenously using Chan's (1993) method, as described in Enders and Siklos (2001).

In equations (1a) and (1b), we allow for potential short-run asymmetric adjustments through the interaction of the Heaviside Indicator with the lagged firstdifferences of the conventional mortgage interest rate and the effective federal funds rate. Several investigations include potential short-run asymmetries, while others do not. For example, Payne's (2006a, 2006b, and 2007) study concerning U.S. mortgage

\footnotetext{
${ }^{2}$ We use the long-run parameters estimated in Table 2. We do not assume complete pass-through in subsequent results.
} 
interest rates and Becker, Osborn, and Yildirim's (2012) research on U.K. mortgage interest rates exclude these short-run interactions. Valadkhani and Anwar (2012), however, estimate potential short-run asymmetries in Australia. The inclusion of these short-run interactions is a more general, less restrictive specification, as suggested by Enders and Siklos (2001). Further, other research uses this method. For example, research investigating the co-movement of gasoline and oil prices uses this approach [see, for example, Chen, Finney, and Lai (2005) or Bumpass, Ginn, and Tuttle (2015)].

The primary coefficients of interest in equation (1a) are $\gamma$ and $\pi$. The coefficients $\gamma_{1}, \gamma_{2}$, and $\gamma_{3}$ measure the short-run response of the mortgage interest rate to changes in the effective federal funds rate when the error-correction variable is greater than $\tau$. The $\pi$ coefficients, alternatively, measure the response of the mortgage interest rate to changes in the effective federal funds rate when the error-correction term is below the threshold. Specifically, the test for short-run symmetry in the mortgage interest rate in response to changes in the effective federal funds rate is $\gamma=\pi$. The coefficients $\beta$ and $\alpha$ measure the short-run changes in the mortgage interest rate to lagged changes in the mortgage interest rate when the error-correction term is above the threshold and below the threshold, respectively. Similar coefficients in the federal fund rate equation measure the response of the effective federal funds rate in the same manner.

In Table 3, the threshold parameter, $\tau$, is set to zero. Therefore, the adjustment parameters, $\delta_{1}$ and $\delta_{2}$, yield the adjustment of the mortgage interest rate relative to the long-run equilibrium derived in Table 2 . For example, when $\varepsilon_{t-1}$ is greater than zero, the conventional mortgage interest rate is above its long-run value, given by $\theta_{1} E F F_{\mathrm{t}-1}+\theta_{2}$. The long-run adjustment parameters and the short-run response parameters provide the immediate adjustment of the mortgage interest rate and the federal funds rate when the mortgage interest rate is above or below equilibrium. In more general terms, starting at long-run equilibrium, the error-correction term is positive in periods where the effective federal funds rate is falling and it is negative in periods when the effective federal funds rate is increasing.

The results in Table 3 suggest that the conventional mortgage interest rate responds symmetrically to changes in the federal funds rate in the long run, given by the test of equality of the long-run adjustment parameters, $\delta_{1}$ and $\delta_{2}$. The estimated half-life of adjustment in the conventional mortgage interest rate in Table 3 is between fifteen and twenty-four months. ${ }^{3}$

\footnotetext{
${ }^{3}$ The half-life is an estimate of the number of months required to eliminate half of the long-run disequilibrium caused by changes in the federal funds rate. The half-life is calculated via $t=(\operatorname{Ln}(0.5)) /\left(\operatorname{Ln}\left(1+\delta_{\mathrm{i}}\right)\right)$.
} 
Given the results from estimating equation (1b), we fail to reject the strict exogeneity of the effective federal funds rate, i.e. we fail to reject the joint hypothesis that the long-run adjustment parameters and the short run mortgage interest rate parameters are statistically zero with an associated p-value of $0.602(\mu=\omega=\sigma=0)$. Therefore, the long-run equilibrium adjustment between these two rates is resolved solely through changes in the conventional mortgage rate in Table 3.

Table 3

TAR Results, $\tau=0$

\begin{tabular}{|c|c|c|c|c|c|}
\hline \multicolumn{3}{|c|}{$\Delta \mathrm{MR}$ Equation } & \multicolumn{3}{|c|}{$\Delta$ EFF Equation } \\
\hline & Value & p-value & & Value & p-value \\
\hline$\delta_{1}$ & -0.044 & 0.011 & $\mu_{1}$ & -0.020 & 0.588 \\
\hline$\delta_{2}$ & -0.029 & 0.105 & $\mu_{2}$ & 0.036 & 0.458 \\
\hline$\rho_{0}$ & 0.006 & 0.740 & $\rho_{1}$ & 0.036 & 0.444 \\
\hline$\beta_{1}+\beta_{2}+\beta_{3}$ & 0.195 & 0.033 & $\omega_{1}+\omega_{2}+\omega_{3}$ & -0.044 & 0.797 \\
\hline$\alpha_{1}+\alpha_{2}+\alpha_{3}$ & 0.158 & 0.380 & $\sigma_{1}+\sigma_{2}+\sigma_{3}$ & -0.018 & 0.975 \\
\hline$\gamma_{1}+\gamma_{2}+\gamma_{3}$ & 0.115 & 0.027 & $\varphi_{1}+\varphi_{2}+\varphi_{3}$ & 0.420 & 0.000 \\
\hline \multirow[t]{2}{*}{$\pi_{1}+\pi_{2}+\pi_{3}$} & 0.084 & 0.155 & $\lambda_{1}+\lambda_{2}+\lambda_{3}$ & 0.268 & 0.283 \\
\hline & F-statistic & p-value & & F-statistic & p-value \\
\hline$\delta_{1}=\delta_{2}$ & 0.266 & 0.606 & $\mu_{1}=\mu_{2}$ & 0.514 & 0.474 \\
\hline$\delta_{1}=\delta_{2}=0$ & 8.492 & 0.000 & $\mu_{1}=\mu_{2}=0$ & 0.278 & 0.758 \\
\hline$\beta_{1}=\ldots=\beta_{\mu}=\alpha_{1}=\ldots=\alpha_{\mu}$ & 20.062 & 0.000 & $\omega_{1}=\ldots=\omega_{\mu}=\sigma_{1}=\ldots=\sigma_{\mu}$ & 1.225 & 0.296 \\
\hline$\beta_{1}=\ldots=\beta_{\mu}=\alpha_{1}=\ldots=\alpha_{\mu}=0$ & 17.627 & 0.000 & $\omega_{1}=\ldots=\omega_{\mu}=\sigma_{1}=\ldots=\sigma_{\mu}=0$ & 1.035 & 0.402 \\
\hline$\gamma_{1}=\ldots=\gamma_{\mu}=\pi_{1}=\ldots=\pi_{\mu}$ & 3.392 & 0.005 & $\varphi_{1}=\ldots=\varphi_{\mu}=\lambda_{1}=\ldots=\lambda_{\mu}$ & 5.472 & 0.000 \\
\hline$\gamma_{1}=\ldots=\gamma_{\mu}=\pi_{1}=\ldots=\pi_{\mu}=0$ & 4.399 & 0.000 & $\varphi_{1}=\ldots=\varphi_{\mu}=\lambda_{1}=\ldots=\lambda_{\mu}=0$ & 6.986 & 0.000 \\
\hline Adjusted $\mathrm{R}^{2}$ & & 0.345 & Adjusted $\mathrm{R}^{2}$ & & 0.273 \\
\hline
\end{tabular}

In all estimations, the method of Newey-West is used.

As mentioned, previous research concerning U.S. mortgage interest rate asymmetries does not investigate potential short-run asymmetries in either interest rate. In this specification, the short-run response of the mortgage interest rate due to changes in itself and changes in the effective federal funds rate is asymmetric in Table 3. Specifically, we reject the null hypothesis that the short-run interactions are equal. The results indicate that the response of the mortgage interest rate to changes in the effective federal funds rate is larger when the mortgage interest rate is greater than its long-run equilibrium rate $(\Sigma \pi<\Sigma \gamma)$. In other words, the mortgage interest rate exhibits larger short-run changes when the effective federal funds rate is falling relative to periods when the federal funds rate is rising. The difference, however, is not large economically.

The results in Table 3 also suggest short-run asymmetric changes in the federal funds rate to lagged changes in itself, relative to the threshold. For example, the sum of the coefficients $\varphi_{1}, \varphi_{2}$, and $\varphi_{3}$ are statistically and economically larger than $\lambda_{1}, \lambda_{2}$, and $\lambda_{3}$. This means the effective federal funds rate exhibits a larger 
response to its own lagged changes in periods where the effective federal funds rate is falling. Therefore, there are larger adjustments in the effective federal funds rate in periods where this rate is falling during periods of expansionary policy.

In Table 4, the threshold value is determined endogenously and, is therefore, less restrictive than the specification used to derive results in Table 3. Results, available upon request, yield a value of $\tau$ equal to -1.39 . Combining the results from Table 2, the derivation of $\tau$ yields the following:

$$
\begin{gathered}
\tau>\varepsilon_{t-1}=M R_{t-1}-0.9 * E F F_{t-1}-3.446 \\
-1.39>M R_{t-1}-0.9 * E F F_{t-1}-3.446 \\
M R_{t-1}-0.9 * E F F_{t-1}<2.056
\end{gathered}
$$

The value of $\tau$ indicates that the mortgage interest rate may respond differently during periods of aggressive contractionary policy, i.e. when the spread between the two interest rates given by the long-run relationship is, roughly, two percentage points or less due to large and/or frequent increases in the effective federal funds rate. From January 1990 through the end of the sample, the difference between the mortgage interest rate and the federal funds rate was less than two percent in sixty-nine of the three hundred fourteen months and occurs during periods of contractionary policy by the Federal Reserve. For example, during the two-year period from January 2006 through January 2008, the spread, or difference between the mortgage interest rate and the federal funds rate averaged 1.4 percentage points, and the spread was below 2.056 percent during the entire period. During these periods, the short-run response of the mortgage interest rate to changes in the federal funds rate may differ relative to other periods. The short-run response of the mortgage interest rate during these periods of aggressive contractionary policy is given by the $\pi$ coefficients.

The long-run adjustment results for the mortgage interest rate, in Table 4 , are statistically and economically similar to those of Table 3 . We fail to reject the null hypothesis of the long-run symmetric response of the mortgage interest rate. Further, relative to Table 3, there is less disparity between the two long-run adjustment parameters $\left(\delta_{1}\right.$ and $\left.\delta_{2}\right)$ in the mortgage interest rate equation. The halflife of adjustment of the mortgage interest rate here is between nineteen and twentytwo months. 
Table 4

TAR Results, $\tau=-1.39$

\begin{tabular}{|c|c|c|c|c|c|}
\hline \multicolumn{3}{|c|}{$\Delta \mathrm{MR}$ Equation } & \multicolumn{3}{|c|}{$\Delta$ EFF Equation } \\
\hline & Value & $\mathrm{p}$-value & & Value & $\mathrm{p}$-value \\
\hline$\delta_{1}$ & -0.035 & 0.001 & $\mu_{1}$ & -0.006 & 0.694 \\
\hline$\delta_{2}$ & -0.031 & 0.076 & $\mu_{2}$ & 0.016 & 0.732 \\
\hline$\rho_{0}$ & -0.004 & 0.653 & $\rho_{1}$ & 0.017 & 0.352 \\
\hline$\beta_{1}+\beta_{2}+\beta_{3}$ & 0.233 & 0.006 & $\omega_{1}+\omega_{2}+\omega_{3}$ & 0.121 & 0.433 \\
\hline$\alpha_{1}+\alpha_{2}+\alpha_{3}$ & -0.103 & 0.641 & $\sigma_{1}+\sigma_{2}+\sigma_{3}$ & -0.817 & 0.179 \\
\hline$\gamma_{1}+\gamma_{2}+\gamma_{3}$ & 0.091 & 0.038 & $\varphi_{1}+\varphi_{2}+\varphi_{3}$ & 0.578 & 0.000 \\
\hline \multirow[t]{2}{*}{$\pi_{1}+\pi_{2}+\pi_{3}$} & 0.185 & 0.006 & $\lambda_{1}+\lambda_{2}+\lambda_{3}$ & 0.209 & 0.470 \\
\hline & F-statistic & $\mathrm{p}$-value & & F-statistic & $\mathrm{p}$-value \\
\hline$\delta_{1}=\delta_{2}$ & 0.052 & 0.820 & $\mu_{1}=\mu_{2}$ & 0.209 & 0.648 \\
\hline$\delta_{1}=\delta_{2}=0$ & 6.853 & 0.001 & $\mu_{1}=\mu_{2}=0$ & 0.144 & 0.866 \\
\hline$\beta_{1}=\ldots=\beta_{\mu}=\alpha_{1}=\ldots=\alpha_{\mu}$ & 20.585 & 0.000 & $\omega_{1}=\ldots=\omega_{\mu}=\sigma_{1}=\ldots=\sigma_{\mu}$ & 1.508 & 0.186 \\
\hline$\beta_{1}=\ldots=\beta_{\mu}=\alpha_{1}=\ldots=\alpha_{\mu}=0$ & 18.505 & 0.000 & $\omega_{1}=\ldots=\omega_{\mu}=\sigma_{1}=\ldots=\sigma_{\mu}=0$ & 1.595 & 0.146 \\
\hline$\gamma_{1}=\ldots=\gamma_{\mu}=\pi_{1}=\ldots=\pi_{\mu}$ & 3.756 & 0.002 & $\varphi_{1}=\ldots=\varphi_{\mu}=\lambda_{1}=\ldots=\lambda_{\mu}$ & 4.860 & 0.000 \\
\hline$\gamma_{1}=\ldots=\gamma_{\mu}=\pi_{1}=\ldots=\pi_{\mu}=0$ & 5.095 & 0.000 & $\varphi_{1}=\ldots=\varphi_{\mu}=\lambda_{1}=\ldots=\lambda_{\mu}=0$ & 7.145 & 0.000 \\
\hline Adjusted $R^{2}$ & & 0.387 & Adjusted $\mathrm{R}^{2}$ & & 0.385 \\
\hline
\end{tabular}

In all estimations, the method of Newey-West is used.

The short-run adjustment in the mortgage interest rate to its own lagged changes in Table 4 is also similar to those of Table 3. The results show, however, larger short-run changes in the mortgage interest rate due to changes in the effective federal funds rate when $\tau$ is less than -1.39 , or when the spread between these two rates is around 2.056 or less. The short-run adjustment of the mortgage interest rate to lagged changes in the effective federal funds rate, when it is below the threshold, is larger relative to its above-threshold short-run adjustment. Therefore, these results indicate an asymmetric short-run response of the mortgage interest rate during periods of aggressive contractionary monetary policy.

Again, we find strict exogeneity in the effective federal funds rate ( $\mathrm{p}$-value of 0.267). In addition, like the results in Table 3, the effective federal funds rate responds asymmetrically to lagged changes in itself in the short run with larger shortrun changes when the federal funds rate is falling. This indicates that the Federal Reserve produced larger, more frequent reductions in the federal funds rate, relative to periods where the federal funds rate was increasing.

Finally, Table 5 provides the results from the MTAR model, which is similar to the method employed by Payne (2006a). In the MTAR model, the threshold is endogenously determined using lagged changes in the error-correction term. In other words, the adjustment process may be different for larger positive or negative changes in the error-correction term relative to smaller positive or negative changes.

Using the method of Chan, our threshold value for $\tau$ is -0.075 . A change in 
the error-correction term, i.e. a change in the size of amount of disequilibrium, of less than -0.075 percentage points, holding the mortgage interest rate constant, may cause a different response in the mortgage interest rate relative to a change in the error-correction term that is greater than -0.075 percentage points.

In the MTAR results, the Heaviside Indicator equals one when the change in the error-correction term is positive. The change in the error-correction term is positive when the mortgage interest rate is increasing to restore long-run equilibrium. Therefore, the $\gamma$ coefficients give the short-run change in the mortgage interest rate due to changes in the effective federal funds rate when the mortgage interest rate is increasing to restore long-run equilibrium. Alternatively, the $\pi$ coefficients provide the short-run change in the mortgage interest rate when this rate is decreasing.

\section{Table 5}

MTAR Results, $\tau=-\mathbf{0 . 0 7 5}$

\begin{tabular}{|c|c|c|c|c|c|}
\hline \multicolumn{3}{|c|}{$\Delta \mathrm{MR}$ Equation } & \multicolumn{3}{|c|}{$\Delta \mathrm{EFF}$ Equation } \\
\hline & Value & p-value & & Value & $\mathrm{p}$-value \\
\hline$\delta_{1}$ & -0.046 & 0.004 & $\mu_{1}$ & -0.003 & 0.914 \\
\hline$\delta_{2}$ & -0.034 & 0.005 & $\mu_{2}$ & 0.026 & 0.469 \\
\hline$\rho_{0}$ & 0.001 & 0.923 & $\rho_{1}$ & -0.016 & 0.685 \\
\hline$\beta_{1}+\beta_{2}+\beta_{3}$ & 0.198 & 0.067 & $\omega_{1}+\omega_{2}+\omega_{3}$ & 0.083 & 0.802 \\
\hline$\alpha_{1}+\alpha_{2}+\alpha_{3}$ & 0.147 & 0.479 & $\sigma_{1}+\sigma_{2}+\sigma_{3}$ & -0.202 & 0.740 \\
\hline$\gamma_{1}+\gamma_{2}+\gamma_{3}$ & 0.101 & 0.124 & $\varphi_{1}+\varphi_{2}+\varphi_{3}$ & 0.378 & 0.072 \\
\hline \multirow[t]{2}{*}{$\pi_{1}+\pi_{2}+\pi_{3}$} & 0.047 & 0.415 & $\lambda_{1}+\lambda_{2}+\lambda_{3}$ & 0.316 & 0.156 \\
\hline & F-statistic & p-value & & F-statistic & p-value \\
\hline$\delta_{1}=\delta_{2}$ & 0.560 & 0.455 & $\mu_{1}=\mu_{2}$ & 0.344 & 0.558 \\
\hline$\delta_{1}=\delta_{2}=0$ & 6.316 & 0.002 & $\mu_{1}=\mu_{2}=0$ & 0.263 & 0.769 \\
\hline$\beta_{1}=\ldots=\beta_{\mu}=\alpha_{1}=\ldots=\alpha_{\mu}$ & 18.231 & 0.000 & $\omega_{1}=\ldots=\omega_{\mu}=\sigma_{1}=\ldots=\sigma_{\mu}$ & 1.286 & 0.269 \\
\hline$\beta_{1}=\ldots=\beta_{\mu}=\alpha_{1}=\ldots=\alpha_{\mu}=0$ & 16.033 & 0.000 & $\omega_{1}=\ldots=\omega_{\mu}=\sigma_{1}=\ldots=\sigma_{\mu}=0$ & 1.758 & 0.106 \\
\hline$\gamma_{1}=\ldots=\gamma_{\mu}=\pi_{1}=\ldots=\pi_{\mu}$ & 2.772 & 0.018 & $\varphi_{1}=\ldots=\varphi_{\mu}=\lambda_{1}=\ldots=\lambda_{\mu}$ & 5.545 & 0.000 \\
\hline$\gamma_{1}=\ldots=\gamma_{\mu}=\pi_{1}=\ldots=\pi_{\mu}=0$ & 2.991 & 0.007 & $\varphi_{1}=\ldots=\varphi_{\mu}=\lambda_{1}=\ldots=\lambda_{\mu}=0$ & 9.359 & 0.000 \\
\hline Adjusted $\mathrm{R}^{2}$ & & 0.327 & Adjusted $\mathrm{R}^{2}$ & & 0.244 \\
\hline
\end{tabular}

In all estimations, the method of Newey-West is used.

Table 5 supports Payne's (2006a) long-run results. We find that the effective federal funds rate is strictly exogenous (p-value of 0.171 ), and the mortgage interest rate responds symmetrically in the long run. Further, the sizes of the adjustment parameters for the mortgage interest rate are similar to those in Table 3.

We extend the work of Payne by examining potential asymmetric short-run changes in the conventional mortgage interest rate. We find, in this specification, that the mortgage interest rate responds asymmetrically to changes in both interest rates in the short run. Specifically, the mortgage interest rate exhibits faster shortrun changes in response to lagged changes in both interest rates when the mortgage interest rate is increasing to restore long-run equilibrium (when the lagged change 
in the error-correction term is greater than -0.075$)^{4}$. These results support those of Table 4 and show that the mortgage interest rate experiences larger changes in the short run in periods where the mortgage interest rate is increasing due to contractionary monetary policy.

The results for the effective federal funds rate in Table 5 are similar to those in Table 3 and Table 4. Again, we find strict exogeneity in the effective federal funds rate. Further, the effective federal funds rate responds asymmetrically to its own lagged changes, as found in Tables 3 and 4.

Summarizing the short-run results for the mortgage interest rate, we find a general asymmetric response. First, the mortgage interest rate responds asymmetrically to its own lagged changes. Further, there is an asymmetric shortrun response of the mortgage interest rate to lagged changes in the federal funds rate. There are some similarities in results across these three tables. First, the shortrun response of the mortgage interest rate, during periods of expansionary policy (increases the error-correction term above the threshold value or the change in the error-correction term is negative), is similar in Tables 3, 4, and 5. The difference between the results in these three tables occurs when the effective federal funds rate increases. In Table 3 , the sum of the $\pi$ coefficients are statistically zero when the threshold equals zero. Table 4's results show, however, that the response of the mortgage interest rate to increases in the federal funds rate is identical to its response when the federal funds rate decreases, but only when the increases in the federal funds rate are "small," well-dispersed increases. During periods of large and frequent increases in the federal funds rate due to contractionary policy, however, the size of the short-run changes in the mortgage interest rate increases. In Table 5 , the short-run change in the mortgage interest rate is larger in periods where the mortgage interest rate is increasing to restore long-run equilibrium.

These results suggest that the mortgage interest rate closely follows the effective federal funds rate. In fact, the failure to reject complete pass-through suggests a one-to-one movement in the long run with an average spread of 3.45 percentage points, with the mortgage interest rate responding symmetrically in the long run. Further, the mortgage interest rate displays short-run asymmetric adjustment to changes in the federal funds rate. Less restrictive results in Tables 4 and 5 show that the mortgage interest rate exhibits larger increases in the short run during periods of aggressive contractionary policy.

\footnotetext{
${ }^{4}$ The sums of the two sets of short-run coefficients for the effective federal funds rate are statistically zero. The results, however, reject the null hypothesis that all short run coefficients for the effective federal funds rate are statistically zero.
} 


\section{CONCLUSION}

We reexamine the relationship between the conventional thirty-year mortgage interest rate and the effective federal funds rate. The Johansen test suggests that the two interest rates are cointegrated. Further, we fail to reject the null hypothesis of complete pass-through, and, therefore, conclude mortgage lenders appear to maintain a constant margin in the long run.

Like previous research, we fail to reject the null hypothesis of symmetric long-run adjustment in the mortgage interest rate in all specifications. Further, we find the effective federal funds rate is strictly exogenous in all specifications. The results in all models indicate a short-run asymmetric response in the mortgage interest rate to changes in both interest rates. In the short run, results show larger changes in the mortgage interest in the short run during periods of contractionary monetary policy. In other words, long-run mortgage market imperfections, such as asymmetric information, may not be as great as that indicated in some of the previous research. This research demonstrates that potential market imperfections cited in previous literature appear temporary in nature.

\section{REFERENCES}

Banerjee, A., J. Donaldo, J. Galbraith, \& D. Hendry. (1993). "Co-integration, ErrorCorrection, and the Econometric Analysis of Nonstationary Data." Advanced Texts in Econometrics. Oxford University Press, Oxford, UK.

Bardsen, G. (1989). "Estimation of Long Run Coefficients in Error Correction Models." Oxford Bulletin of Economics and Statistics, 51, 345 - 350.

Becker, R., Osborn, D., \& Yildirim, D. (2012). "A Threshold Cointegration Analysis

of Interest Rate Pass-Through to UK Mortgage Rates." Economics Modelling, $29,2504-2513$.

Bumpass, D., Ginn, V., \& Tuttle, M. (2015). "Retail and Wholesale Gasoline Price Adjustments in Response to Oil Price Changes." Energy Economics, 52, 49 54.

Chan, K. (1993). "Consistency and Limiting Distribution of the Least Squares Estimator of a Threshold Autoregressive Model." The Annals of Statistics, 21, $520-533$.

Chen, L. M. Finney and Lai, K. (2005). "A Threshold Cointegration Analysis of Asymmetric Price Transmission from Crude Oil to Gasoline Prices." Economic Letters, 89, 233 - 239. 
Cook, S. (2008). "Econometric Analysis of Interest Rate Pass-Through." Applied Financial Economics Letters, 4, 249 - 251.

Dickey, D. and Fuller, W.A. (1979). "Distribution of the Estimates for Autoregressive Time Series with a Unit Root." Journal of the American Statistical Association, $74,427-431$.

Enders, W. and Siklos, P. (2001). "Cointegration and Threshold Adjustment." Journal of Business and Economic Statistics, 19, 304 - 311.

Engle, R. and Granger, C. (1987). "Cointegration and Error Correction: Representation, Estimation, and Testing." Econometrica, 55, 251 - 276.

Grange, C. and Newbold, P. (1974). "Spurious Regressions in Econometrics." Journal of Econometrics, 2, 111 - 120.

Hegwood, N. and Tuttle, M. (2013). "A Comment on Tests for Asymmetric Threshold Cointegration with an Application to the Term Structure: Cointegration Methods Matter." Journal of Economics, 39, 73 - 77.

Hjelm, G. and Johansson, M. (2005). "A Monte Carlo Study on the Pitfalls in Determining Deterministic Components in Cointegration Models." Journal of Macroeconomics, 27, $691-703$.

Johansen, S. (1991). "Estimation and Hypothesis Testing of Cointegrating Vectors in Gaussian Vector Autoregressive Models." Econometrica, 59, 1551 - 1580.

Kwiatkowski, D., Phillips, P., Schmidt, P. \& Shin, Y. (1992). "Testing the Null Hypothesis of Stationarity Against the Alternative of a Unit Root: How Sure Are We That Economic Time Series Have a Unit Root?" Journal of Econometrics, $54,159-178$.

Payne, J. (2006a). "The Response of the Conventional Mortgage Rate to the Federal Funds Rate: Symmetric or Asymmetric Adjustment?" Applied Financial Economics Letters, 2, 279 - 284.

Payne, J. (2006b). "More on the Monetary Transmission Mechanism: Mortgage Rates and the Federal Funds Rate." Journal of Post Keynesian Economics, 29, $247-257$.

Payne, J. (2007). "Interest Rate Pass-Through and Asymmetries in Adjustable Rate Mortgages." Applied Financial Economics, 17, 1369 - 1376.

Perron, Pierre. (1989). "The Great Crash, the Oil Price Shock, and the Unit Root Hypothesis." Econometrica, 57, 1361 - 1401.

Perron, Pierre, \& Vogelsang, Timothy J. (1992). "Nonstationarity and Level Shifts with an Application to Purchasing Power Parity." Journal of Business and Economic Statistics, 10, $301-320$. 
Sellon, George. (2002). "The Changing U.S. Financial System: Some Implications for the Monetary Transmission Mechanism." Federal Reserve Bank of Kansas City Economic Review, 1st Quarter, 5 - 35.

Valadkhani, A. and Anwar, S. (2012). "Interest Rate Pass Through and the Asymmetric Relationship Between the Cash Rate and the Mortgage Rate." The Economic Record, 88, 341 - 350.

\section{BIOGRAPHICAL SKETCH OF AUTHORS}

Natalie Hegwood is a Clinical Assistant Professor at Sam Houston State University in the Department of Economics and International Business. She received her Ph.D. from the University of Houston. Her research interests include International Monetary Economics and Applied Time Series Econometrics. She has published articles in International Journal of Finance and Economics, Southern Economic Journal, Midwestern Business and Economic Review, The Journal of Economics, Journal of Macroeconomics, and Economic Analysis and Policy.

M. H. Tuttle is an Associate Professor of Economics in the Department of Economics and International Business at Sam Houston State University. He earned his Ph.D. from the University of Tennessee. Professor Tuttle teaches macroeconomics, managerial economics, and statistics. He has published in several peer-reviewed journals including Energy Economics, Defense and Peace Economics, Southern Economic Journal, Economic Inquiry, and the Journal of Economics. 